\title{
Post-ERCP pancreatogastric fistula associated with an intraductal papillary-mucinous neoplasm of the pancreas - a case report and literature review
}

\author{
Masaru Koizumi*, Naohiro Sata, Koji Yoshizawa, Munetoshi Tsukahara, \\ Katsumi Kurihara, Yoshikazu Yasuda and Hideo Nagai
}

Address: Department of Surgery, Jichi Medical School, 3311-1, Yakushiji Minamikawachi Tochigi, 329-0498, Japan

Email: Masaru Koizumi* - mkoizumi@jichi.ac.jp; Naohiro Sata - sata@jichi.ac.jp; Koji Yoshizawa - k-yoshi@jichi.ac.jp; Munetoshi Tsukahara - m-tsuka@jichi.ac.jp; Katsumi Kurihara - kkurihar@jichi.ac.jp; Yoshikazu Yasuda - yyasuda@jichi.ac.jp; Hideo Nagai - nagaihd@jichi.ac.jp

* Corresponding author

Published: 19 October 2005

World Journal of Surgical Oncology 2005, 3:70 doi:10.1 186/1477-7819-3-70

This article is available from: http://www.wjso.com/content/3/I/70

(c) 2005 Koizumi et al; licensee BioMed Central Ltd.

This is an Open Access article distributed under the terms of the Creative Commons Attribution License (http://creativecommons.org/licenses/by/2.0), which permits unrestricted use, distribution, and reproduction in any medium, provided the original work is properly cited.
Received: 03 June 2005

Accepted: 19 October 2005

\begin{abstract}
Background: Fistula formation has been reported in intraductal papillary-mucinous neoplasms (IPMNs) with or without invasion of the adjacent organs. The presence or absence of invasion is mostly determined by postoperative histological examination rather than by preoperative work-up.

Case presentation: A 72 year-old Japanese woman showed remarkable dilatation of the main pancreatic duct (MPD) in the distal region of the pancreas. Subsequent ERCP also showed MPD dilatation, after which the patient suffered moderate pancreatitis. A subsequent gastroscopy revealed a small ulceration that had not been observed in a gastroscopy performed 3 months prior. Mucinous discharge from the ulceration suggested it might be the orifice of a fistula connected to the MPD. En bloc resection including the distal region of the pancreas, spleen, stomach and part of the transverse colon was performed under the pre- and intraoperative diagnosis of an invasive malignant IPMN. However, histopathology revealed the lesion to be of "borderline malignancy" without apparent invasion of the stomach. Light microscopy showed inflammatory cellular infiltrates (mainly neutrophils) around the pancreatogastric fistula, but there was no evidence of neoplastic epithelia lining the fistulous tract.
\end{abstract}

Conclusion: This case highlights that a pancreatogastric fistula can develop after acute inflammation of the pancreas in the absence of cancer invasion. Further information regarding IPMN-associated fistulae is necessary to clarify the pathogenesis, diagnosis, appropriate surgical intervention and prognosis for this disorder.

\section{Background}

Intraductal papillary-mucinous neoplasms (IPMNs) of the pancreas have unique clinico-pathological characteristics and show a wide spectrum of histological types, ranging from adenomatous hyperplasia to invasive cancer.
While non-invasive IPMNs show slow growth and good prognosis after resection, the outcome can become poor if they transform into invasive ductal cancers. There are three types of IPMN: main duct,, branch, and combined. 


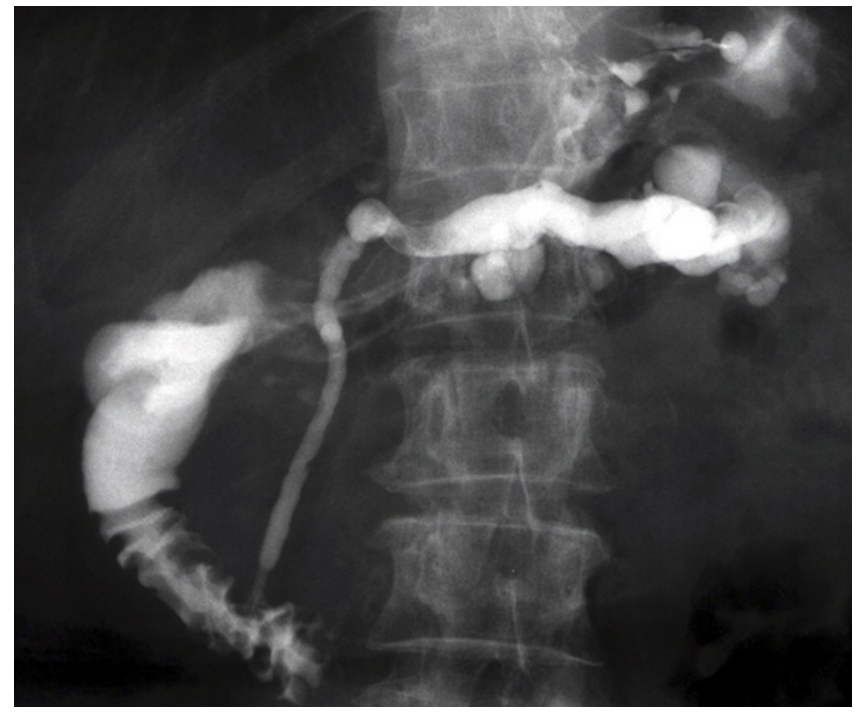

Figure I

ERCP on presentation showing a dilated MPD and cystic lesions in the distal region of the pancreas.

The main duct and combined types are associated with higher rates of invasive cancer than the branch type [1].

A feature of IPMNs is occasional fistula formation with surrounding organs such as the duodenum, bile ducts, stomach and even the peritoneal or pleural cavity [2-10]. While such fistula formation is generally thought to be associated with invasive IPMNs, some non-invasive IPMNs also form fistulas. Thus, IPMN fistula formation raises intriguing issues concerning pathogenesis, diagnosis and patient prognosis.

We report here a rare non-invasive "borderline-malignant" IPMN that formed a pancreatogastric fistula. Fistula formation was triggered by acute pancreatitis following endoscopic retrograde cholangiopancreatography (ERCP).

\section{Case presentation}

A 72 year-old Japanese woman underwent abdominal ultrasonography (US) as part of a routine physical checkup in April 2001. This procedure incidentally detected marked dilatation of the main pancreatic duct (MPD) in the distal region of the pancreas. Magnetic resonance cholangiopancreatography (MRCP) and abdominal computed tomography (CT) showed MPD dilatation and a multi-lobular cystic lesion. ERCP confirmed these findings, and no extraluminal leakage of the contrast medium was observed (Figure 1). Cytology on pancreatic fluid indicated non-neoplastic epithelia. Endoscopic

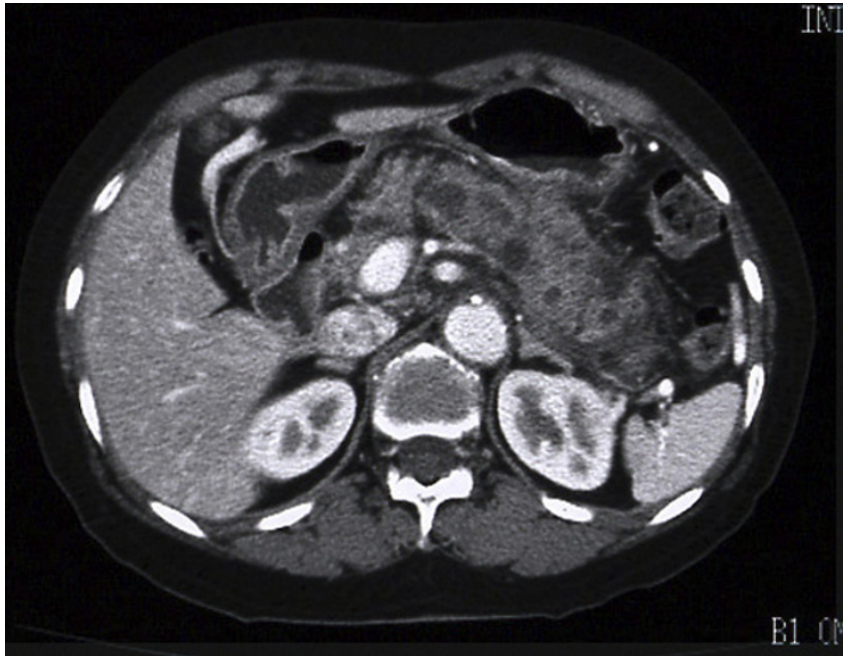

Figure 2

Abdominal CT just prior to surgery showing distinct swelling of the pancreas and the gastric wall, causing the border between the two organs to be unclear.

ultrasonography (EUS) identified $8 \mathrm{~mm}$ papillary projections in the cystic lesion, which was a key indication for surgery. A routine gastroscopy performed simultaneously with EUS showed no significant findings.

Following the ERCP, the patient complained of abdominal pain and showed hyperamylasemia and leukocytosis. Distinct swelling of the pancreas and thickening of the gastric wall were subsequently observed by abdominal CT (Figure 2), which indicated a mild post-ERCP pancreatitis. Gastroscopy performed for the assessment of gastric wall thickness revealed a small ulceration in the body of the stomach (Figure 3), which was accompanied by a mucinous discharge suggesting the presence of a fistula opening into the MPD. These findings, along with abdominal angiography data indicating encasement of the splenic artery suggested a malignant invasion into the stomach by the primary lesion. All other laboratory data, including tumor marker expression (e.g., CEA and CA19-9), were within normal limits.

A laparotomy was performed 1 month after the ERCP. Firm fibrous tissue between the pancreas and the mesenterium of the transverse colon suggested the pancreatic neoplasm was of an invasive nature. An en bloc resection of the distal pancreas, spleen, stomach and part of the transverse colon was performed. Postoperative histopathology showed the distal pancreas had an IPMN whose lining epithelia showed only "borderline-malignancy" and no apparent invasion of adjacent tissues or organs. Light 


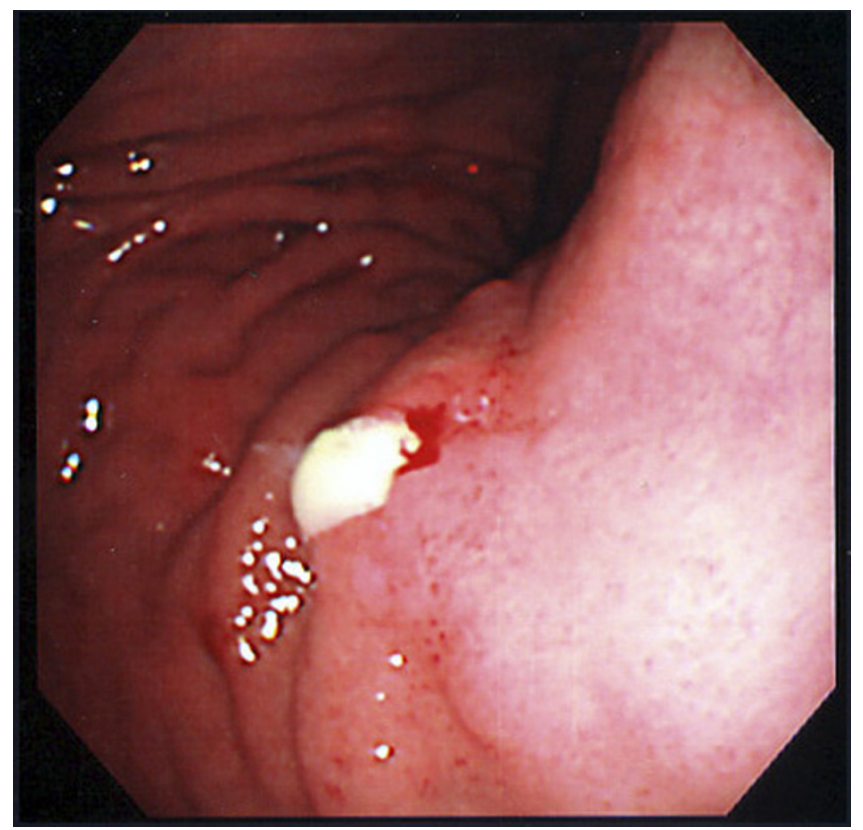

Figure 3

Gastroscopy just prior to surgery showing a small ulcer producing a mucinous discharge into the body of the stomach.

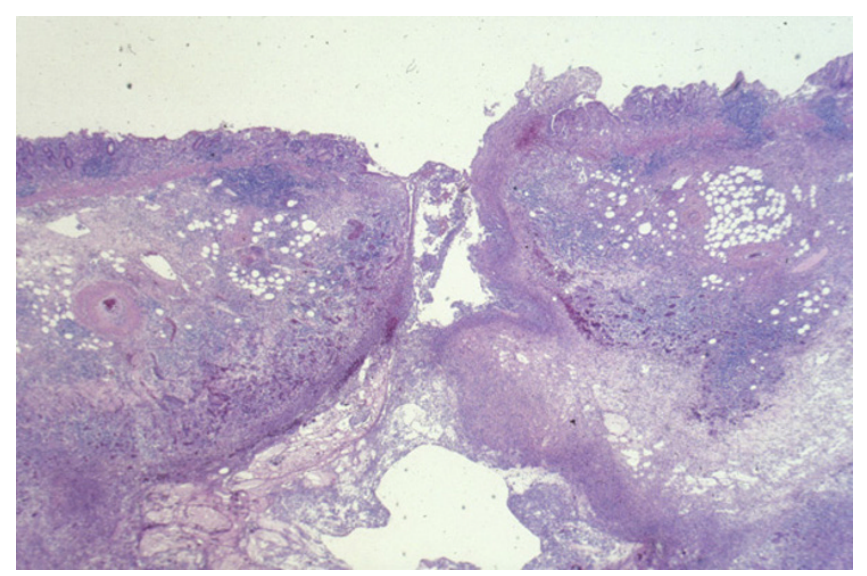

Figure 4

A cross-section of the pancreatogastric fistula (Hematoxylin and Eosin stain $\times 40$ ). The fistula was significantly infiltrated with neutrophils and showed no evidence of neoplastic infiltration.

microscopy examination revealed inflammatory cellular infiltration consisting mainly of neutrophils around a pancreatogastric fistula which had no neoplastic epithelia
(Figure 4). The patient was discharged after an uneventful postoperative recovery and showed no signs of recurrence 3 years after surgery.

\section{Discussion}

Fistula formation associated with an IPMN was first reported by Ohhashi et al in 1980 as a pancreatobiliary fistula [2]. Since then there have been 41 cases reported between 1980 and 2004 (Table 1) [3-9]. According to these reports, the organs most frequently affected by fistula formation were the duodenum (24 cases, 59\%), common bile duct (21 cases, 51\%) and stomach (7 cases, $17 \%)$. Apparent cancer invasion was the main cause of the fistulae in 16 cases (37\%), while similar to the present case, 17 cases (41\%) showed fistulae into neighboring organs in the absence of tumor invasion (Table 2). Five of the six previous IPMN cases associated with pancreatogastric fistulae were linked to apparent cancer invasion.

To our knowledge, the present report is only the second describing a case of IPMN associated with pancreatogastric fistulae without invasive cancer. Yago et al reported a rare case of non-invasive intraductal papillary adenocarcinoma of the pancreas that was associated with development of a pancreatogastric fistula in the absence of cancer invasion [5]. In that case, neoplastic epithelia were observed only on the surface of the fistula and gastric mucosa, while the structure of the gastric wall beside the fistula was maintained without invasive cancer. Those authors speculated that the pancreatogastric fistula developed due to high pressure in the MPD. Baek et al and Watanabe et al reported the same phenomenon in mucinous cystic tumors (MCTs) [11,12]. The mechanism of such fistula formation without cancer spread could be explained by a combination of high pressure in the MPD and inflammatory stimulation $[3,4,13]$.

In the present case, ERCP played a key role in fistula formation. To our knowledge, this is the first report to show an absence of a pancreatogastric fistula immediately prior to ERCP, and then the presence of a fistula following postERCP pancreatitis. Post-ERCP pancreatitis, which is reported to occur in approximately $1.8-10 \%$ of patients, should be carefully investigated in IPMN cases $[14,15]$.

We emphasize here that development of an IPMN-associated fistula does not necessarily represent underlying invasive cancer. Fistula formation can result in an incorrect preoperative diagnosis of invasive cancer and lead to the undertaking of unnecessary surgical procedures. Although the lesion in the present case was a non-invasive tumor, surgery was appropriate given the indications of invasive cancer. While non-invasive IPMNs have a good prognosis, there remains the possibility of dissemination by tumor penetration. When treating IPMNs associated 
Table I: Published cases of developing fistulae from IPMNs (1980-2004)

\begin{tabular}{|c|c|c|c|c|c|}
\hline No. & Author & Year & Affected Organs & Cancer Invasion & $\begin{array}{l}\text { Pathological } \\
\text { Diagnosis }\end{array}$ \\
\hline 1 & Ohhashi [2] & 1980 & C & - & cystadenocarcinoma \\
\hline 2 & Koike [3] & 1980 & C, D & unknown & pap \\
\hline 3 & Sukisaki [3] & 1984 & S, D & + & pap (+ muc) \\
\hline 4 & Usui [3] & 1985 & $\mathrm{D}$ & - & pap \\
\hline 5 & Suyama [3] & 1986 & C & + & pap \\
\hline 6 & Suyama [3] & 1986 & D & + & pap \\
\hline 7 & Yamao [3] & 1986 & $\mathrm{D}$ & unknown & pap \\
\hline 8 & Yamao [3] & 1986 & C & unknown & pap \\
\hline 9 & Yamao [3] & 1986 & C & unknown & pap \\
\hline 10 & Miyagawa [3] & 1988 & C, D & + & pap (+ muc) \\
\hline 11 & Kuga [3] & 1988 & D & - & pap \\
\hline 12 & Tohyama [3] & 1989 & C & - & pap \\
\hline 13 & Nakajima [3] & 1989 & C & - & pap \\
\hline 14 & Ohnuma [3] & 1990 & $\mathrm{~S}$ & + & pap (+ muc) \\
\hline 15 & Sakimoto [3] & 1991 & C & + & pap (+ muc) \\
\hline 16 & Mayumi [3] & 1991 & C, D & + & muc (+ pap) \\
\hline 17 & Hayashi [3] & 1991 & $C$ & unknown & cystadenocarcinoma \\
\hline 18 & Oda [3] & 1993 & C, D & - & pap \\
\hline 19 & Saitoh [3] & 1993 & C & - & pap \\
\hline 20 & Kobayashi [4] & 1993 & $\mathrm{~S}$ & + & muc (+ pap) \\
\hline 21 & Kobayashi [4] & 1993 & S, D & + & muc (+ pap) \\
\hline 22 & Kobayashi [4] & 1993 & C, D & unknown & pap \\
\hline 23 & Kobayashi [4] & 1993 & $D$ & unknown & pap \\
\hline 24 & Kobayashi [4] & 1993 & $\mathrm{D}$ & unknown & muc (+ pap) \\
\hline 25 & Mori [3] & 1994 & C & + & pap \\
\hline 26 & leda [3] & 1995 & $\mathrm{D}$ & + & tub \\
\hline 27 & Yago [5] & 1995 & $S$ & - & pap \\
\hline 28 & Takekuma [3] & 1996 & $\mathrm{D}$ & - & pap \\
\hline 29 & Nakamura [3] & 1996 & C, D & + & pap \\
\hline 30 & Murata [3] & 1996 & C, D & - & pap \\
\hline 31 & Hirota [3] & 1996 & $\mathrm{D}$ & - & pap \\
\hline 32 & Tadokoro [6] & 1996 & $\mathrm{D}$ & - & unknown \\
\hline 33 & Nakatsuka [3] & 1997 & $S, D$ & + & muc \\
\hline 34 & Matsubayashi [7] & 1998 & $D$ & + & pap \\
\hline 35 & Kawaharada [3] & 1999 & D & + & pap \\
\hline 36 & Kawaharada [3] & 1999 & $\mathrm{D}$ & + & pap \\
\hline 37 & Shiroko [8] & 2000 & C, D & - & unknown \\
\hline 38 & Kurihara [9] & 2000 & C & - & pap \\
\hline 39 & Kurihara [9] & 2000 & C & - & pap \\
\hline 40 & Fujisawa [3] & 2001 & C & - & pap \\
\hline 41 & Koizumi(present case) & 2004 & $\mathrm{~S}$ & - & low grade malignancy \\
\hline
\end{tabular}

Affected Organ; C: Common bile duct, D: Duodenum, S: Stomach Pathological Diagnosis; pap: papillary carcinoma, muc: mucinous carcinoma tub: tubular adenocarcinoma

with fistula, the extent of resection should depend on the extent of cancer invasion. To avoid dissemination, the fistula should be removed independent to cancer invasion. The extent of resection of affected organs should be individually determined based on the results of preoperative images and precise intraoperative histological examinations.

\section{Conclusion}

The present case highlights that a pancreatogastric fistula can develop in the absence of invasive cancer. Further data regarding IPMN-associated fistulae are necessary in order to clarify the pathogenesis, diagnosis, appropriate surgical intervention and prognosis for this disorder. 
Table 2: Organs developing IPMN-associated fistulae (Revised from Table I)

\begin{tabular}{ccccc}
\hline & & \multicolumn{3}{c}{ Cancer invasion } \\
\cline { 3 - 5 } Affected organs & Case & + & - & unknown \\
\hline C & 13 & 3 & 7 & 3 \\
D & 13 & 5 & 5 & 3 \\
C and D & 8 & 3 & 3 & 2 \\
S & 4 & 2 & 2 (this case) & 0 \\
S and D & 3 & 3 & 0 & 0 \\
Total & 41 & 16 & 17 & 8 \\
\hline
\end{tabular}

Affected Organ; C: Common bile duct, D: Duodenum, S: Stomach

\section{Competing interests}

The author(s) declare that they have no competing interests.

\section{Authors' contributions}

MK, NS, KY, MT, KK, YY and HN were involved in performing surgery, undertook the literature search and drafted the manuscript for submission.

HN supervised preparation of the manuscript and edited the final version for publication. All authors read and approved the manuscript.

\section{Acknowledgements}

Patient consent was obtained for publication of case records, MRCP, abdominal CT, ERCP, US, gastroscopy and histopathological images.

\section{References}

I. Sugiyama M, Atomi $Y$ : Intraductal papillary mucinous tumors of the pancreas: imaging studies and treatment strategies. Ann Surg 1998, 228:685-691.

2. Ohhashi K, Tajiri H, Gondo M, Yokoyama Y, Maruyama M, Takekoshi T, Matsuura Y, Kasumi F, Takagi K, Kato Y: A case of cystadenocarcinoma of the pancreas forming bilio-pancratic fistula. Progress of Digestive Endoscopy 1980, 17:261-264.

3. Fujisawa T, Osuga T, Mita M, Sakamoto N, Sakaguchi K, Onishi $Y$, Toyoda M, Maeda M, Kawase Y, Nishigami T: Intraductal papillary adenocarcinoma of the pancreas accompanied by biliopancreatic fistula; report of a case. Ganno Rinsyo (Jpn J Cancer Clin) 200I, 47:|44-I50.

4. Kobayashi G, Fujita N, Noda Y, Kimura K, Watanabe H, Chonan A, Matsunaga A, Yuki T, Ando M, Sato Y, Tominaga G, Mochizuki F, Yamazaki T: Study of cases of mucin producing tumors of the pancreas showing penetration of other organs. Nippon Shokakibyo Gakkai Zasshi (Jpn J Gastroenterology) 1993, 90:308I-3089.

5. Yago A, Fujita N, Noda Y, Kobayashi G, Kimura K, Mochizuki F, Yamazaki T, Ikeda T: A case of non-invasive intraductal papillary adenocarcinoma of the pancreas showing penetration of the stomach. Fukubu Gazo Shindan 1995, I 5:496-500.

6. Tadokoro H, Toki F, Yoshida K, Nishino T, Kojima S, Shiratori K, Watanabe S, Kozu T, Takeuchi T, Hayashi N, Imaizumi T, Suzuki S: Two cases of pancreaticoduodenal fistula. Gastroenterological Endoscopy 1996, 38:1208-13.

7. Matsubayashi H, Kokuno S, Itoi T, Mizumura Y, Niki S, Takeda K, Onoda K, Ogiwara M, Ohno H, Horibe T, Miwa K, Shinohara Y, Mag- ami Y, Niido T, Seki T, Saitoh T: A case of intraductal papillary adenocarcinoma of the pancreas with pancreatico-duodenal fistula. Progress of Digestive Endoscopy 1998, 52:180-I81.

8. Shiroko J, Takai S, Yoshikawa T, Ohnishi T, Nakai M, Asano H, Tanabashi S, Kametani M, Okamoto K: A case of Mucin-producing pancreatic cancer penetrating to the common bile duct and the duodenum. Ganno Rinsyo (Jpn J Cancer Clin) 2000, 46:967-97I.

9. Kurihara K, Nagai H, Kasahara K, Kanazawa K, Kanai N: Biliopancreatic fistula associated with intraductal papillary-mucinous pancreatic cancer: institutional experience and review of the literature. Hepato-Gastroenterology 2000, 47: I I 64-I I 67.

10. Inoue M, Ikeda Y, Kikui M, Ogawa T, Yasumitsu T: Mucin-producing tumor of the pancreas associated with pyothorax: report of a case. Surg Today 200I, 3 I:538-54I.

I I. Baek Y, Midorikawa T, Nagasaki H, Kikuchi H, Kitamura N, Takeuchi S, Koh Y, Yagi H, Yoshizawa $Y$, Kumada N: A case report of pancreatic mucinous cystadenocarcinoma with penetration to the stomach. Nippon Shokakibyo Gakkai Zasshi Upn J Gastroenterology) 1999, 96:685-690.

12. Watanabe N, Hasegawa H, Tsuneya Y, Kumazawa M, Baba M, Kusano I, Watanabe M, Yamao $Y$ : A case of mucinous cystadenocarcinoma with a fistula between cyst and stomach. Nippon Shokakibyo Gakkai Zasshi (Jpn J Gastroenterology) 2003, I 00:349-353.

13. Fukushima N, Mukai K: Mechanism of invasion through the duct wall by intraductal papillary adenocarcinoma of the pancreas. Tan to Sui (J Bil Panc) 1999, 20:17-20.

14. Pannu HK, Fishman EK: Complications of endoscopic retrograde cholangiopancreatography: Spectrum of abdominalities demonstrated with CT. Radio Graphics 200 I, 2 I : |44 I- | 453.

15. Masci E, Toti G, Mariani A, Curioni S, Lomazzi A, Dinelli M, Minoli G, Crosta C, Comin U, Fertitta A, Prada A, Passoni GR, Testoni PA: Complications of diagnostic and therapeutic ERCP: A prospective multicenter study. Am J Gastroenterol 200I, 96:4I 7-423.

Publish with Biomed Central and every scientist can read your work free of charge

"BioMed Central will be the most significant development for disseminating the results of biomedical research in our lifetime. "

Sir Paul Nurse, Cancer Research UK

Your research papers will be:

- available free of charge to the entire biomedical community

- peer reviewed and published immediately upon acceptance

- cited in PubMed and archived on PubMed Central

- yours - you keep the copyright

Submit your manuscript here:

http://www.biomedcentral.com/info/publishing_adv.asp
BioMedcentral 